La melatonina como hormona reguladora del sueño

Muchos de los procesos bioquímicos y fisiológicos del organismo humano están sujetos a un ciclo circadiano que se repite aproximadamente cada 24 horas y que se ve determinado por osciladores endógenos fotosensibles en el sistema nervioso central (SNC). Como parte de este ciclo la glándula pineal, que sirve de interfase principal entre el medio ambiente luminoso, el sistema endocrino y el SNC, sintetiza la hormona melatonina a partir del triptófano y la libera hacia la circulación, donde alcanza sus concentraciones máximas en horas de la noche. Esta hormona inductora del sueño a su vez actúa en el SNC por mediación de receptores específicos (ML-1, ML-2, ML RR).

$\mathrm{Su}$ efecto regulador del ciclo circadiano confiere a la melatonina propiedades idóneas para tratar el insomnio por alteración del ritmo natural del sueño en viajeros con jet lag y trabajadores con turnos irregulares, por dar ejemplos, aunque sirve para cualquier tipo de insomnio. Esta hormona tiene muy poca toxicidad y no se han documentado efectos secundarios graves, pero la falta de información sobre sus efectos a largo plazo hace necesaria su farmacovigilancia a lo largo del tiempo.

La melatonina se ha administrado por vía oral y endovenosa y por inhaladores, parches dérmicos y parches gingivales. Se recomienda la administración de 2 a $5 \mathrm{mg}$ de 30 a 60 minutos antes de dormir, aunque en ensayos clínicos se han administrado dosis de $1 \mathrm{~g}$ diario por varios meses con un mínimo de efectos adversos y sin signos de toxicidad hepática, renal o de médula ósea. En general, las pruebas acumuladas hasta ahora sugieren que la acción fisiológica de la melatonina se debe a la combinación de tres efectos: la inducción del sueño; la sincronización del ciclo natural del sueño y la vigilia; y la reducción de la temperatura corporal.

La melatonina se está usando en todo el mundo, a menudo sin supervisión médica adecuada. Se ha demostrado en los Estados Unidos de América que muchos de los productos que se venden en tiendas naturistas y que dicen contener cierta concentración de melatonina en realidad contienen una cantidad mucho menor de la indicada en el envase. Aunque se trata de una sustancia inocua y eficaz, urge prestar atención al control de su calidad. (Cardinali DP. Aplicaciones terapéuticas de la melatonina en la medicina del sueño y en la psiquiatría. Acta Psiquiat Psicol Am Lat 1996;42:127-136.)

\section{Interrupción de la transmisión de la enfermedad de Chagas en el Brasil}

La enfermedad de Chagas existe solamente en las Américas. Su agente causal, el protozoario flagelado Trypanosoma cruzi, penetra en el organismo humano principalmente por la picadura de insectos hematófagos del género Triatoma. La enfermedad de Chagas es crónica, incurable, discapacitante y mortal y suele concentrarse en focos ecológicos bien definidos donde la presencia simultánea de animales mamíferos y del vector permite que su transmisión se perpetúe, con o sin la participación de seres humanos.

El riesgo de contraer la enfermedad de Chagas se relaciona directamente con factores socioeconómicos, dada la tendencia de Triatoma a alojarse en agujeros en las paredes de viviendas rústicas en el campo y en urbanizaciones pobres. Tras las grandes migraciones del campo a la ciudad de los años setenta, la enfermedad se convirtió en una afección urbana transmisible por transfusión sanguínea.

A excepción de la malaria y la esquistosomiasis, la tripanosomiasis es la enfermedad tropical que constituye mayor sobrecarga para los servicios de salud. Se calcula que en las Américas las pérdidas económicas anuales asociadas con esta enfermedad se aproximan a US\$ 6500 millones, suma que equivale a $1,3 \%$ de la deuda externa de todo el territorio. En el Brasil, cerca de 30\% de las personas infestadas a la larga sufren trastornos cardíacos y digestivos graves, como arritmias, megaesófago y megacolon.

En 1970, la tripanosomiasis era endémica en más de $36 \%$ del territorio brasileño. T. infestans, especie doméstica, era el vector principal de la enfermedad y se asociaba con las mayores tasas de infestación parasitaria. En 1975 se lanzó el Programa Nacional para el Control de la Enfermedad de Chagas, cuya estrategia se centró en el rociamiento de viviendas con insecticidas. Su éxito fue rotundo, ya que en 1982 T. infestans fue eliminado del estado de São Paulo y entre 1982 y 1993 el número de municipalidades infestadas con esta especie en el resto del país se redujo en $89 \%$. En Mato Grosso y Goiás la eliminación fue casi com- 
pleta y los únicos focos de infestación actual se encuentran en los estados de Bahia, Tocantins y Rio Grande do Sul. En 1994 se hicieron encuestas seroepidemiológicas de niños de 7 a 14 años en 10 estados endémicos y se encontraron reacciones positivas en menos de $0,5 \%$ de los casos en nueve de esos estados, resultado que apunta a una reducción de más de 96,0\% desde 1980. En otras palabras, la transmisión vectorial de la enfermedad en este territorio prácticamente ha sido eliminada. Se ha observado, asimismo, una enorme reducción de las muestras de sangre positivas a T. cruzi en los bancos de sangre. Actualmente las actividades de control se dirigen a eliminar $T$. infestans de los pocos focos restantes en Bahia, Goiás y Rio Grande do Sul para 1998. (World Health Organization. Chagas disease. Wkly Epidemiol Rec 1997;72:1-8.)

\section{Recomendaciones en torno a la vacunación antipoliomielítica}

Los Centros para el Control y la Prevención de Enfermedades (CDC), en Atlanta, Georgia, Estados Unidos de América, han aceptado las recomendaciones de su Comité Consultivo sobre Prácticas de Inmunización y han modificado el régimen de vacunación antipoliomielítica en el país a partir de principios de 1997. Los Centros recomiendan que los niños estadounidenses reciban dos dosis inyectadas de virus inactivados (una a los 2 meses de edad y la otra a los 4), seguidas de dos dosis de vacuna oral a base de virus vivos atenuados (la primera entre los 12 y los 18 meses y la segunda entre los 4 y 6 años de edad). Este nuevo régimen se ha ideado con el fin de prevenir los ocho o nueve casos de poliomielitis yatrógena que se presentan en el país cada año.

La poliomielitis, que en Estados Unidos atacaba a millares de personas en los años cincuenta, ha dejado de ser un problema de salud pública, ya que desde 1979 no se ha notificado ningún caso de parálisis causada por el poliovirus salvaje. Este logro monumental se atribuye al uso generalizado de la vacuna oral, que protege no solo a la persona vacunada, sino también a otras personas susceptibles porque al diseminarse el virus de la vacuna en la comunidad se frena la propagación del poliovirus salvaje. Aunque la vacuna inyectada a base de virus inactivados confiere un grado de protección similar, no se considera tan eficaz como la vacuna oral para prevenir la diseminación comunitaria del poliovirus salvaje entre personas susceptibles.

Fuera de los Estados Unidos, las recomendaciones en torno a la vacunación son distintas. Los CDC, junto con el Fondo de las Naciones Unidas para la Infancia y el Club Rotario Internacional, anunciaron en noviembre de 1995 su apoyo a la política de inmunización recomendada por la OMS para la erradicación mundial de la poliomielitis. La política consiste en administrar a niños en países donde aún circula el poliovirus salvaje solamente la vacuna oral debido a su mayor eficacia directa e indirecta, a la facilidad de su administración y a su bajo costo (US\$ 0,08 por dosis). La poliomielitis fue erradicada del hemisferio occidental en 1994 y se espera lograr su erradicación del mundo entero para el año 2000. (World Health Organization. Polio vaccination in the United States. EPI Newsletter 1996;XVIII:5-6.)

\section{La autoprescripción responsable de medicamentos adquiribles sin receta}

En la 12. ${ }^{a}$ Reunión Anual de la Federación Mundial de Fabricantes de Medicamentos que se celebró en Toronto, Canadá, en octubre de 1996, el Director de la OMS señaló las ventajas y desventajas de la autoprescripción de los fármacos adquiribles sin receta médica y declaró que su uso responsable puede mejorar el estado de salud de personas en el mundo entero. Simultáneamente instó a los delegados de la Reunión a apoyar el uso racional de los medicamentos y recomendó a los Estados que adaptaran a sus circunstancias particulares los criterios éticos delineados por la OMS en 1988 para la promoción de sustancias medicamentosas.

En junio de 1995 un Comité de Expertos de la OMS llegó a la conclusión de que la automedicación responsable puede "ayudar a prevenir y tratar afecciones que no requieren una consulta médica" y "aminorar la sobrecarga que tienen los servicios médicos como consecuencia del tratamiento de afecciones menores". El Director de la OMS se expresó a favor de la automedicación para el tratamiento de la diarrea infantil y de la anemia en mujeres, pero advirtió al mismo tiempo que una excesiva dependencia de los fármacos autorrecetados puede redundar en la búsqueda atrasada de atención médica, el uso inadecuado de fármacos mal rotulados o sin instrucciones y el desarrollo de microorganismos resistentes.

En general, el Director hizo hincapié en la necesidad de un sistema de automedicación inocua y racional, respaldado por medidas dirigidas no solo a asegurar el uso apropiado de los productos mismos, sino también a su promoción, monitoreo y comercialización adecuados. Algunas metas serían la inclusión en el envase de información fácil de entender y la diseminación de materiales educati- 
vos en las escuelas y centros de salud. Por último el Director de la OMS declaró que "si se ha de lograr el uso seguro de estos medicamentos, es imprescindible que las autoridades sanitarias, el personal de salud, los gremios de profesionales, las asociaciones de pacientes y las organizaciones de consumidores colaboren entre sí y con la industria farmacéutica". (World Health Organization. Dr. Nakajima calls for responsible self-medication. Comunicado de prensa WHO/72, 29 de octubre de 1996.)

\section{¿Cuán beneficioso es el tratamiento de la hipertensión en la edad avanzada?}

El tratamiento de la hipertensión arterial en pacientes de edad avanzada es un tema que sigue suscitando controversia. Existe la creencia generalizada de que la hipertensión en este grupo es poco peligrosa e incluso hay quienes opinan, con justificación, que en presencia de aterosclerosis avanzada cualquier medida para bajar la tensión arterial puede reducir el flujo de sangre al cerebro y provocar hipotensión postural y hasta infarto cerebral. Según pruebas recientes, sin embargo, el tratamiento de la hipertensión es más beneficioso que perjudicial, en términos generales. Se han realizado ensayos clínicos aleatorios a gran escala cuyos resultados han demostrado claramente que el tratamiento de la hipertensión moderada en pacientes ancianos reduce el riesgo general de trastornos cardiovasculares.

Uno de los objetivos principales del tratamiento en el grupo citado es proteger contra los accidentes cerebrovasculares tromboembólicos. Se calcula que de los 400000 accidentes cerebrovasculares que ocurren anualmente en los Estados Unidos de América, más de las tres cuartas partes se asocian con hipertensión arterial. Algunos estudios de cohortes han demostrado que en este sentido la tensión diastólica es un factor determinante y que la asociación no disminuye cuando la tensión es menor de $80 \mathrm{mmHg}$. En un estudio prospectivo de 5 años en pacientes con hipertensión diastólica exclusivamente, el tratamiento antihipertensivo redujo la incidencia de accidentes cerebrovasculares en $66 \%$ y la tasa de mortalidad por todas las causas en $13 \%$.

Ya que el riesgo de un accidente cerebrovascular es mayor en personas de edad avanzada, los resultados de estos estudios constituyen una prueba convincente de los beneficios de tratar la hipertensión diastólica y sistólica en este grupo. Aunque sería disparatado caer en generalizaciones, ya que el riesgo de accidente cerebrovascular varía en distintas poblaciones, actualmente el control de la tensión arterial es la medida más eficaz para reducir el riesgo de un accidente cerebrovascular. Es posible que también reduzca el riesgo de demencia, puesto que se ha observado una asociación entre esta y la hipertensión, pero aún no se ha confirmado ningún beneficio en este sentido. Más bien, existe el temor de que los hipotensores reduzcan la perfusión sanguínea cerebral hasta el punto de exacerbar el deterioro mental propio de la senilidad. (World Health Organization. Raised blood pressure in the elderly. WHO Drug Info 1996;10:72-74.)

\section{La reaparición de algunas enfermedades de transmisión alimentaria}

Algunas enfermedades transmitidas por los alimentos, aunque ya conocidas, se consideran en reaparición porque en años recientes su frecuencia ha aumentado notablemente. Por ejemplo, durante varias décadas la salmonelosis tuvo brotes esporádicos, pero en las últimas dos su incidencia se ha incrementado en todas partes. En el mundo occidental, Salmonella del serotipo enteritidis se ha convertido en la cepa predominante y su reaparición se atribuye principalmente al consumo de aves y huevos contaminados. En 1994 se produjo un brote generalizado de salmonelosis en los Estados Unidos de América debido al transporte de helado pasteurizado en recipientes contaminados. Se calcula que alrededor de 224000 personas fueron afectadas por el brote.

Aunque por años el cólera ha devastado grandes partes del Asia y del África, su reintroducción en el hemisferio occidental en 1991, después de casi un siglo de latencia, es un ejemplo de la reciente reaparición de enfermedades infecciosas ya conocidas. El cólera es una enfermedad de propagación principalmente hídrica pero también alimentaria. En América Latina, el hielo y los productos de mar crudos o mal cocidos constituyen vehículos epidemiológicos importantes para la transmisión de la enfermedad.

A diario aparecen agentes patógenos de transmisión alimentaria. Algunos son verdaderamente nuevos y otros son nuevos solo en apariencia porque previamente se desconocía el papel de los alimentos en su transmisión. Constituyen ejemplos Escherichia coli serotipo 0157:H7, Listeria monocytogenes y ciertos trematodos. En general, el fenómeno se debe a numerosos factores, entre ellos el aumento de los viajes y del comercio internacional; la adaptación ecológica de los microbios; las innovaciones en las técnicas de producción de alimentos; los grandes desplazamientos humanos en situaciones de guerra o desastre; y los cambios del estilo de 
vida, entre ellos el consumo más frecuente de comida en restaurantes y quioscos callejeros.

Todas las enfermedades de transmisión alimentaria representan un peligro para el bienestar individual, familiar y nacional y su control exige un esfuerzo concertado por parte de los gobiernos, los consumidores y la industria de comestibles. Como parte de su extensa campaña educativa sobre el tema, la OMS ha publicado The 10 golden rules for safe food preparation y una guía titulada Safe food for travellers. (World Health Organization. Emerging foodborne diseases. Fact Sheet No. 124, noviembre de 1996.)

\section{El consumo de cocaína durante el embarazo: su detección y efectos}

La cocaína, que afecta al sistema nervioso central (SNC) y periférico de los adultos, también puede causar alteraciones estructurales del SNC fetal y un deterioro de la función neurológica del neonato. No obstante, existe controversia sobre la magnitud de estos efectos. En un estudio de 17466 embarazadas en Illinois, Estados Unidos de América, las madres adictas a la cocaína tuvieron un riesgo aumentado de retraso del crecimiento intrauterino, usualmente asociado con microcefalia, debido al paso transplacentario reducido de nutrientes. También mostraron una mayor tendencia al parto prematuro y al desprendimiento placentario como resultado de un aumento de la contractilidad uterina. En los últimos 5 años, varios estudios sobre las manifestaciones clínicas posnatales de la exposición a la cocaína in útero han revelado la presencia de un síndrome neurológico transitorio y de poca gravedad caracterizado por alteraciones del sueño, temblores, rechazo de la alimentación, irritabilidad y, en algunos casos, convulsiones. Este cuadro se acompaña de anormalidades electroencefalográficas que se resuelven espontáneamente entre el primero y sexto mes de vida. Algunos estudios también han demostrado un mayor riesgo de síndrome de muerte súbita del neonato. Los efectos a largo plazo de la cocaína en el desarrollo neurológico y cognoscitivo aún se desconocen, debido a la dificultad de cuantificarlos con las pruebas convencionales.

Según estadísticas recientes derivadas de hospitales urbanos en Argentina, de 10 a $45 \%$ de las embarazadas que son atendidas en estos centros han usado cocaína durante la gestación. El problema también se observa, aunque con menos frecuencia, en zonas periurbanas.

Aunque la anamnesis suele ser útil para detectar la exposición materna a drogas durante el embarazo, la medición de los metabolitos circulan- tes en los vasos del cordón umbilical es más confiable, ya que muchas madres niegan su drogadicción. La única limitación del método es que solo refleja una exposición reciente. La medición de cocaína o sus metabolitos en la orina de la madre o el neonato posee la misma desventaja. En cambio, la cuantificación de los depósitos de estas sustancias en el pelo del neonato permite detectar cualquier exposición transplacentaria en los últimos 3 o 4 meses del embarazo, que es cuando el pelo empieza a salir. Por último, se pueden medir los metabolitos de la cocaína en el meconio. (Alter A y Delbene A. Efectos adversos de la cocaína durante la gestación y en el período neonatal. Rev Hosp Niños Buenos Aires 1996;XXXVIII:253-260.)

\section{¿Puede el consumo de sal en la niñez afectar a la tensión arterial del adulto?}

En una reciente reunión de la Sociedad Internacional de Hipertensión que tuvo lugar en Glasgow, Escocia, se presentaron varios estudios cuyos resultados demuestran que la dieta materna durante el embarazo afecta al riesgo del neonato de padecer de hipertensión arterial en la adultez. Un grupo de investigadores holandeses encontró que mientras más bajo era el peso de un niño al nacer, mayor era su riesgo de ser un adulto hipertenso. La conclusión es que la nutrición materna afecta a la tensión arterial del neonato. Otro estudio en los Países Bajos reveló que los lactantes con una dieta baja en sal durante los primeros 6 meses de vida solían tener más baja la tensión arterial en la edad madura.

Si bien la nutrición en la etapa intrauterina predispone a la hipertensión arterial, factores genéticos y otros relacionados con el estilo de vida, tales como el estrés en el trabajo, el consumo excesivo de alcohol o de sal y la vida sedentaria, ulteriormente ejercen la influencia decisiva. Un grupo de investigadores de la Universidad de Cornell en Nueva York estudió a casi 300 trabajadores de sexo masculino y encontró que los que se sentían más agobiados por las responsabilidades del trabajo tenían más elevada la tensión arterial. Los que indicaron sentir un estrés más intenso tenían tensiones arteriales equivalentes a las de hombres 20 años mayores o que pesaban 40 libras $(18 \mathrm{~kg}$ ) más. Según una especialista de la Universidad de Cambridge, Inglaterra, las presiones del trabajo suelen generar una mayor tendencia a consumir alcohol, a comer sal en exceso y a tener hábitos menos sanos en general, lo cual impide sopesar fácilmente la influencia individual de cada factor. No obstante, los resultados obtenidos por la misma investigadora coinciden con los de otros estudios, según los cuales el estrés 
por sí solo puede causar hipertensión. (The Caribbean Food and Nutrition Institute. High blood pressure? Blame your job, your mother. Cajanus 1996;29:153-154.)

\section{La epidemiología del cáncer de piel en el Brasil}

La piel es el órgano que con más frecuencia se ve afectado por lesiones malignas. Se calcula que $50 \%$ de todas las personas de raza blanca mayores de 60 años tendrán algún tipo de neoplasia cutánea, aunque la incidencia exacta se desconoce porque muchas lesiones no son notificadas por el médico o no se llegan a diagnosticar. El problema es más acentuado en países tropicales, como el Brasil, debido a la intensidad de los rayos solares y a la frecuente exposición al sol.

Según un estudio retrospectivo de las fichas clínicas de 545 pacientes de ambos sexos y de todas las edades con un diagnóstico anatomopatológico seguro de melanoma (6 casos), carcinoma basocelular (447 casos) y carcinoma escamocelular (92 casos), $62,9 \%$ de los pacientes eran de sexo femenino, $98,2 \%$ eran de raza blanca y $67,1 \%$ tenían más de 60 años de edad. Los síntomas y signos más frecuentes fueron, en orden, una lesión cutánea con agrandamiento paulatino, prurito y sangrado, aunque no siempre hubo cambios patentes. La zona del cuerpo más afectada (75,2\% de todos los casos) fue la parte superior de la cara, debido a su mayor exposición al sol. También se detectaron, aunque con menos frecuencia, lesiones en el tórax $(12,1 \%)$, en miembros superiores $(8,4 \%)$ y en miembros inferiores $(4,2 \%)$. El cáncer escamocelular fue particularmente común en el labio inferior, así como en las orejas, la cara y los miembros superiores. De todos los pacientes estudiados, 30,1\% habían sido tratados previamente por algún tipo de cáncer de piel.

Todos los pacientes habían tenido una excisión quirúrgica de la lesión maligna y 302 regresaron a hacerse un seguimiento al cabo de 3 meses; 181 al cabo de 6; 94 al cabo de 12, y 28 al cabo de 24 . Aunque debido a la poca asistencia a las visitas de seguimiento no se pueden sacar conclusiones válidas acerca de los resultados del tratamiento, en general se observó un aumento significativo del número de recidivas a los 12 meses que pone de relieve la importancia del seguimiento de pacientes sometidos a cualquier tipo de tratamiento para el cáncer de la piel. Muchos de los pacientes presentaron, además, lesiones malignas nuevas en el período posquirúrgico. Esto confirma los resultados descritos en la bibliografía sobre la elevada frecuencia de lesiones múltiples, sobre todo en pacientes con carcinoma basocelular. (D'Apparecida S. Machado Filho C, et al. Neoplasias malignas cutâneas: estudo epidemiológico. Anais Brasil Dermatol 1996;71:479-484.) 